\title{
Laccase-catalyzed decolorization and detoxification of Acid Blue 92: statistical optimization, microtoxicity, kinetics, and energetics
}

Shahla Rezaei ${ }^{1}$, Hamed Tahmasbi ${ }^{1}$, Mehdi Mogharabi ${ }^{1,2}$, Alieh Ameri ${ }^{3}$, Hamid Forootanfar ${ }^{4}$, Mohammad Reza Khoshayand ${ }^{5}$ and Mohammad Ali Faramarzi ${ }^{1,2^{*}}$

\begin{abstract}
Background: In recent years, enzymatic-assisted removal of hazardous dyes has been considered as an alternative and eco-friendly method compared to those of physicochemical techniques. The present study was designed in order to obtain the optimal condition for laccase-mediated (purified from the ascomycete Paraconiothyrium variabile) decolorization of Acid Blue 92; a monoazo dye, using response surface methodology (RSM). So, a D-optimal design with three variables, including $\mathrm{pH}$, enzyme activity, and dye concentration, was applied to optimize the decolorization process. In addition, the kinetic and energetic parameters of the above mentioned enzymatic removal of Acid Blue 92 was investigated.
\end{abstract}

Results: Decolorization of Acid Blue 92 was maximally ( $94.1 \% \pm 2.61$ ) occurred at pH 8.0, laccase activity of $2.5 \mathrm{U} / \mathrm{mL}$, and dye concentration of $75 \mathrm{mg} / \mathrm{mL}$. The obtained results of kinetic and energetic studies introduced the laccase-catalyzed decolorization of Acid Blue 92 as an endothermic reaction (Ea, $39 \mathrm{~kJ} / \mathrm{mol} ; \Delta \mathrm{S}, 131 \mathrm{~J} / \mathrm{mol} \mathrm{K} ;$ and $\Delta \mathrm{H}$, $40 \mathrm{~kJ} / \mathrm{mol}$ ) with $K_{m}$ and $V_{\text {max }}$ values of $0.48 \mathrm{mM}$ and $227 \mathrm{mM} / \mathrm{min} \mathrm{mg}$, respectively. Furthermore, the results of microtoxicity study revealed that the toxicity of laccase-treated dye was significantly reduced compared to the untreated dye.

Conclusions: To sum up, the present investigation introduced the Paraconiothyrium variabile laccase as an efficient biocatalyst for decolorization of synthetic dye Acid Blue 92.

Keywords: Enzyme Biocatalysis, Optimization, Waste Treatment, Bioremediation, Laccase, Decolorization

\section{Introduction}

The wide usage of synthetic dyes in industries such as textile, paper, plastics, printing, leather, cosmetics, and pharmaceuticals has led to releasing dye containing effluents, rich in complex aromatic structures into the environment $[1,2]$. Almost all synthetic colorants especially the azo dyes - the most common dye group in textile dyeing processes - and/or their degradation products have been reported to be toxic, mutagenic, and carcinogenic [3]. Resistance of the environmentally hazardous dyes to light, biological treatment procedures,

\footnotetext{
* Correspondence: faramarz@tums.ac.ir

'Department of Pharmaceutical Biotechnology, Faculty of Pharmacy and Biotechnology Research Center, Tehran University of Medical Sciences, P.O. Box 14155-6451, Tehran 1417614411, Iran

${ }^{2}$ Pharmaceutical Sciences Research Center, Tehran University of Medical Sciences, Tehran 1417614411, Iran

Full list of author information is available at the end of the article
}

ozone, or other degradative environmental procedures is the main problem in the elimination of dyes discharged from wastewaters $[4,5]$. So, development of efficient and economical processes for treatment of the synthetic dyes still remains as a major challenge [1]. Among various physicochemical and biotechnological techniques, the enzymatic removal of synthetic dyes is the most preferred method due to its simplicity, efficiency at high and low pollutant concentration over a wide range of $\mathrm{pH}$ and temperature, low energy required, minimal impact on ecosystem, and less sludge production in the decolorization process [6-9].

Laccases (benzenediol:oxygen oxidoreductase, EC 1.10.3.2) are multi-copper containing oxidase mainly found in fungi, plants, and some bacterial strains $[5,10]$. The ability of laccases to oxidize a broad range of aromatic compounds such as benzenethiols, substituted phenols, 
and polyaromatic hydrocarbons (PAHs) in the presence of molecular oxygen as a co-substrate introduces this biotechnologically important enzyme as the first choice for xenobiotic removal experiments [11,12]. Decolorization and detoxification of synthetic dyes assisted by laccase and laccase-mediated system (LMS) have received great attention during two last decades $[13,14]$. However, high cost of enzymatic removal (due to low production yield) limits extensive application of laccases in xenobiotic elimination $[15,16]$. This constrain could be overcome via optimization of removal reaction conditions using statistical approaches $[17,18]$.

The response surface methodology (RSM) which is utilized broadly in biotechnological processes, involves a collection of useful statistical and mathematical techniques for analyzing the causal relationship between independent variables, responses, and their interactions through the construction of polynomial mathematical models which leads to time and cost saving [19]. Several studies have been recently published on the potential applications of RSM in the enzymatic decolorization of reactive dyes such as Reactive Black 5, Reactive Red 239, Reactive Yellow 15, and Reactive Blue 114 [16,17].

In the present study, a D-optimal model for RSM as a very useful design method was applied to obtain maximal removal of Acid Blue 92 assisted by laccase. Furthermore, the kinetic and thermodynamic parameters of laccase-mediated dye removal reaction were investigated. The microtoxicity experiments were also performed in order to evaluate the toxicity of untreated and laccasetreated dye.

\section{Materials and methods}

\section{Chemicals}

2,2'-Azino-bis(3-ethylbenzthiazoline-6-sulphonate) (ABTS) was purchased from Sigma-Aldrich (St. Louis, MO, USA). Acid Blue 92 (Figure 1) was kindly donated by Alvan Sabet Co. (Tehran, Iran). All other chemicals and reagents were of the highest purity available. The extracellular laccase of Paraconiothyrium variabile $(P v \mathrm{~L})$ was purified using the method previously described by Forootanfar et al. [20].

\section{Laccase assay}

Laccase activity was determined using ABTS as the substrate [21]. The reaction mixture was prepared by adding $0.5 \mathrm{~mL}$ ABTS $(5 \mathrm{mM})$ dissolved in $100 \mathrm{mM}$ citrate buffer ( $\mathrm{pH} 4.5)$ and $0.5 \mathrm{~mL}$ of enzyme solution followed by incubation at $40^{\circ} \mathrm{C}$ and $120 \mathrm{rpm}$. Oxidation of ABTS was monitored by increase in absorbance at $420 \mathrm{~nm}$ $\left(\varepsilon_{420}=36000 \mathrm{M}^{-1} \mathrm{~cm}^{-1}\right)$ using a UV/vis Spectrophotometer (UVD 2950, Labomed, Culver City, USA). One unit of laccase activity was defined as amount of the enzyme required to oxidize $1 \mu \mathrm{mol}$ of ABTS per min [22].

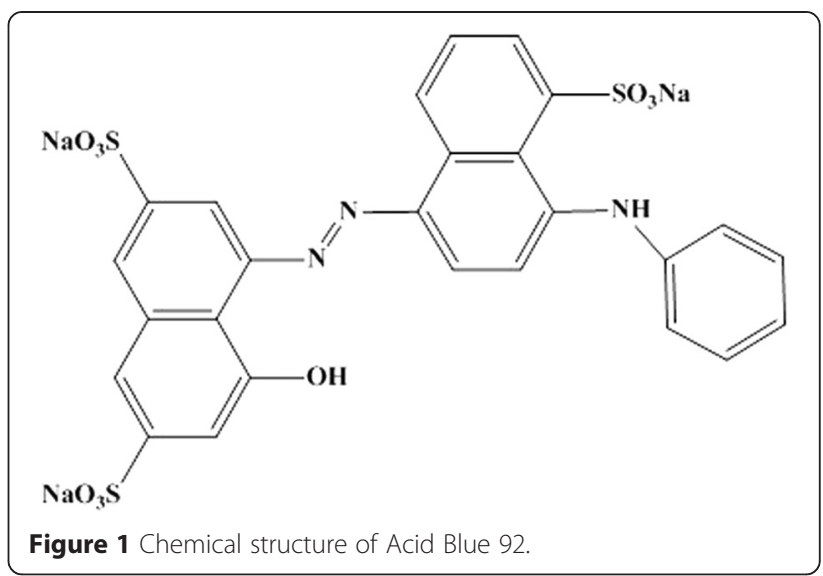

Dye decolorization experiments

After preparation of dye solution (concentration range of $100-200 \mathrm{mg} / \mathrm{L})$ in citrate-phosphate buffer $(0.1 \mathrm{M}$, $\mathrm{pH}$ range of $3.0-8.0$ ), the purified $\mathrm{P} \nu \mathrm{L}$ (final activity of $1-2.5 \mathrm{U} / \mathrm{L}$ ) was added to the reaction mixture and incubated at desired temperature $\left(30-70^{\circ} \mathrm{C}\right)$ for $30-$ 90 min followed by measuring the absorbance of the taken samples using a UV/visible spectrophotometer at maximum absorbance of applied dye $(571 \mathrm{~nm})$. Decolorization percentage was then calculated using the following equation: decolorization $(\%)=\left[A_{i}-A_{t} / A_{i}\right] \times 100$; where $\mathrm{A}_{\mathrm{i}}$ is the initial absorbance of the reaction mixture and $A_{t}$ is the absorbance after incubation time [1]. The negative control (reaction mixture containing the heat-inactivated enzyme) was prepared and incubated at the same conditions. All experiments were performed in triplicate and the means of decolorization percentages were reported.

\section{Experimental design and statistical analysis Screening study}

The screening experiment was designed based on the fractional factorial design method, which is a definite part of full factorial design matrix with two-level factor variations containing $2^{\mathrm{k}-\mathrm{p}}$ runs $\left(1 / 2^{\mathrm{p}}\right.$ fraction of the $2^{\mathrm{k}}$ design); where $\mathrm{k}$ and $\mathrm{p}$ are the number of independent variables and size of the fraction, respectively. Different factors including $\mathrm{pH}(\mathrm{A})$, temperature (B), enzyme activity $(C)$, dye concentration (D), and incubation time (E) were implemented using $2^{5-1}$ fractional factorial design with resolution $\mathrm{V}$. The design matrix was built using the statistical software package, Design-Expert (version 7.0.0; Stat-Ease, Inc., Minneapolis, Minnesota, USA). Factors and corresponding response presented in Table 1. All of the experiments were accomplished in triplicate and the averages considered as responses.

\section{Optimization study}

The D-optimal design developed to select the design points in a method that minimizes the variance associated 
Table 1 Level of independent variables in fractional factorial design

\begin{tabular}{lllll}
\hline Variables & Symbol & Unit & Low level $(\mathbf{- 1})$ & High level $(+\mathbf{1})$ \\
\hline $\mathrm{pH}$ & $\mathrm{A}$ & - & 3 & 8 \\
Temperature & $\mathrm{B}$ & ${ }^{\circ} \mathrm{C}$ & 30 & 70 \\
Enzyme & $\mathrm{C}$ & $\mathrm{U} / \mathrm{mL}$ & 1 & 2.5 \\
Dye & $\mathrm{D}$ & $\mathrm{mg} / \mathrm{L}$ & 100 & 200 \\
Incubation time & $\mathrm{E}$ & $\mathrm{min}$ & 30 & 90 \\
\hline
\end{tabular}

with the estimates of coefficient in a specified model. The number of runs in a D-optimal design are less and do not rise as fast as the classical design with an increasing number of factors. The D-optimal design try to minimize the determinant of the $\left(\mathrm{X}^{\prime} \mathrm{X}\right)^{-1}$ matrix which lead to minimize the volume of the confidence for the coefficients and maximizes the determinant 'information' matrix $\left(\mathrm{X}^{\prime} \mathrm{X}\right)$; where " $\mathrm{X}$ " defined as a matrix containing the designed points generated by the computer to fulfill the D-optimally. The D-optimal designs, as an optimization method based on a chosen optimality criterion, used the determinant of the information matrix $\mathrm{X}^{\prime} \mathrm{X}$. Maximizing the determinant of the information matrix $\left(\mathrm{X}^{\prime} \mathrm{X}\right)$ lead to minimizing the determinant of the matrix $\left(\mathrm{X}^{\prime} \mathrm{X}\right)^{-1}$ which beneficially keep the later calculations as short as possible. Finally, the Fisher's test with P-values below 0.05 employed to evaluate the statistical significance of the effect of independent variables on the response using analysis of variance (ANOVA). While the multiple correlation coefficient $\left(R^{2}\right)$ and adjusted $R^{2}$ used as quality indicators for the fit of secondorder polynomial model equation, contour plots, and three-dimensional surface plots were used to graphically show the relationship and interactions between the coded variables and responses. The optimal condition for enzymatic decolorization process determined by solving the equation derived from the final quadratic model as well as grid search of the three-dimensional surface plots.

\section{Dye removal kinetics and energetics \\ Kinetics of decolorization}

After performing of decolorization reaction in the presence of the dye concentrations $(10-500 \mu \mathrm{M})$ at optimal $\mathrm{pH}$ and temperature, the velocity for different concentrations of dye was determined. Michaelis-Menten curve was then drawn by plotting the obtained initial velocity against dye concentrations. Calculation of $K_{m}$ and $V_{\text {max }}$ values were performed by fitting the data to the Lineweaver-Burk plot, resulting of the MichaelisMenten plot conversion $[1,2]$.

\section{Thermodynamics of decolorization}

In order to evaluate the effect of temperature on removal of Acid Blue 92, decolorization experiment was performed at temperature range of $10-50^{\circ} \mathrm{C}$ and the obtained velocities (for each temperature) were plotted against initial dye concentrations. Thereafter, apparent first-order rate constant (K) for each temperature were calculated from the slope of each straight plot. The value of activation energy $\left(E_{\mathrm{a}}\right)(\mathrm{kJ} / \mathrm{mol})$ was then estimated from the slope of the linearized Arrhenius curve achieved by drawing the $\ln (\mathrm{K})$ versus $1 / \mathrm{T}\left(\times 10^{3} \mathrm{~K}^{-1}\right)$ : slope of Arrhenius plot $=\left(-E_{a} / R\right)$; where $R$ is the gas constant $(8.3145 \mathrm{~J} / \mathrm{mol} \mathrm{K})$, and $\mathrm{T}$ is the absolute temperature $(\mathrm{K})$. The enthalpy $(\Delta \mathrm{H})$ and entropy $(\Delta \mathrm{S})$ of decolorization reaction were estimated by using of Van't Hoff plot which was drawn by plotting the $\ln \left(\mathrm{K}_{\mathrm{eq}}\right)$ against $1 / \mathrm{T}\left(\times 10^{3} \mathrm{~K}^{-1}\right) . \mathrm{K}_{\mathrm{eq}}$ is the apparent equilibrium constant and was calculated from difference of initial dye concentration and residual dye concentration at equilibrium state, when the decolorization percentage become constant and remained dye have no longer changes with passing the time [23]. Finally, the Gibbs free energy $(\Delta G)$ was calculated using the equation of $\Delta \mathrm{G}=\Delta \mathrm{H}-\mathrm{T} \Delta \mathrm{S}$.

\section{Microtoxicity studies}

In order to evaluate the toxicity of produced metabolite(s) following laccase treatment, a series of microtoxicity study was performed. Firstly, a preculture of three Gram-positive bacterial strains (Micrococcus luteus ATCC 10240, Staphylococcus aureus ATCC 6538, and Bacillus subtilis ATCC 6633) and three Gram-negative bacterial strains (E. coli ATCC 25922, Pseudomonas aeruginosa ATCC 9027, and Salmonella typhi ATCC 19430) was prepared by incubating of each bacterial strain in Muller-Hinton broth at $37^{\circ} \mathrm{C}$ and $150 \mathrm{rpm}$ to reach the $\mathrm{OD}_{600}$ of 0.2 . Consequently, the untreated dye solution (final concentration of $100 \mathrm{mg} / \mathrm{L}$ ) and the sample obtained from enzymatic treatment of applied dye (performed at the optimized condition) was separately added to the prepared bacterial culture media and incubated at $37^{\circ} \mathrm{C}$. Changes in the $\mathrm{OD}_{600}$ of each bacterial strain were then recorded every $2 \mathrm{~h}$ for $10 \mathrm{~h}$. A negative control (cultivated bacterial strain in the absence of dye) was designed for each experiment. The percentage of growth inhibition $(\mathrm{GI} \%)$ was defined as $\left[\left(1-\mathrm{D}_{6005} / \mathrm{OD}_{600 \mathrm{C}}\right) \times 100\right]$; where $\mathrm{OD}_{6005}$ is the $\mathrm{OD}_{600}$ of sample and $\mathrm{OD}_{600 \mathrm{C}}$ is the $\mathrm{OD}_{600}$ of control. All experiments were performed in triplicate and mean of the obtained results was reported.

\section{Results and discussion}

\section{Fractional factorial design for screening of important} variables

In a preliminary study, fractional factorial design was used to evaluate the influence of five factors including $\mathrm{pH}(\mathrm{A})$, temperature (B), the enzyme activity (C), dye concentration (D), and incubation time (E) on the decolorization yield in order to select the most effective 
variables on laccase-catalyzed decolorization of Acid Blue 92. The respective high $(+1)$ and low $(-1)$ levels for each coded factor defined in Table 1. A total of 20 runs and the related responses with combination of five mentioned variables were presented in Table 2 . The halfnormal probability plot employed as a graphical tool for estimation the effect of each factor alone and in combination with other factors on decolorization percentage is illustrated in Figure 2. The large distance of $\mathrm{pH}(\mathrm{A})$, enzyme activity $(C)$, and dye concentration (D) from zero in half-normal plot, indicated that these factors significantly affected the decolorization process (Figure 2). In addition, considerable interaction between enzyme activity (C) and dye concentration (D) emerged from half-normal probability plot (Figure 2). In the study of Khouni et al. [24], who applied central composite design (CCD) matrix and RSM for optimization of laccase-mediated decolorization of Black Novacron $\mathrm{R}$ and Blue Bezaktiv S-GLD 150 , two variables including $\mathrm{pH}$ and temperature positively affected decolorization process while the third parameter (laccase activity) did not influence dye removal. Daassi et al. [25] reported the significant effect of four factors (laccase activity,1-hydroxybenzotriazole concentration, dye concentration, and reaction time) on decolorization of Acid Orange 51 assisted by crude laccase from Trametes trogii using a three-level Box-Behnken factorial design combined with response surface methodology to reach $87.87 \pm 1.27$ decolorization percent.

\section{D-optimal design response surface methodology}

Based on the results of the fractional factorial design, three variables, including $\mathrm{pH}(\mathrm{A})$, enzyme activity $(\mathrm{C})$, and dye concentration (D) were found to have a greater influence on the decolorization of Acid Blue 92 assisted by laccase. Therefore, the D-optimal RSM exploited to optimize the affecting decolorization factors. The responses generated from performing a total of 20 runs are presented at Table 3 . Table 4 demonstrates the quadratic model as the most suitable model for the enzymatic decolorization of Acid Blue 92. The analysis of variance for the quadratic model is shown in Table 5 . The model F-value (16.08) shows the significance of the model. In addition, Table 5 indicated $\mathrm{pH}(\mathrm{A})$, dye concentration (D), and their interactions; $\mathrm{AC}, \mathrm{CD}, \mathrm{A}^{2}$ and, $\mathrm{C}^{2}$ as significant model terms (P-value $\left.<0.05\right)$. The quadratic model explained the statistical relationship between the selected variables and the response in terms of coded factors was best fitted with the following equation.

$$
\begin{aligned}
Y= & 18.27+3.99 A+21.55 C-13.5 D \\
& +8.59 A C-5.16 A D-12.37 C D-6.17 A^{2} \\
& +11.42 C^{2}+1.56 D^{2}
\end{aligned}
$$

where $\mathrm{Y}$ is the response (yield of decolorization) and $\mathrm{A}$, $\mathrm{C}$, and $\mathrm{D}$ are $\mathrm{pH}$, enzyme activity, and dye concen-

\begin{tabular}{|c|c|c|c|c|c|c|}
\hline Run no. & $\mathrm{pH}$ & Temperature $\left({ }^{\circ} \mathrm{C}\right)$ & Enzyme activity $(\mathrm{U} / \mathrm{mL})$ & Dye concentration (mg/L) & Incubation time (min) & Response (decolorization\%) \\
\hline 1 & 5.5 & 50 & 1.00 & 100 & 60 & 13.62 \\
\hline 2 & 5.5 & 50 & 1.00 & 100 & 60 & 16.60 \\
\hline 3 & 8.0 & 30 & 2.50 & 50 & 90 & 16.28 \\
\hline 4 & 8.0 & 70 & 2.50 & 200 & 90 & 4.64 \\
\hline 5 & 8.0 & 30 & 0.25 & 200 & 90 & 6.94 \\
\hline 6 & 3.0 & 70 & 2.50 & 200 & 30 & 10.55 \\
\hline 7 & 3.0 & 30 & 2.50 & 200 & 90 & 6.65 \\
\hline 8 & 3.0 & 30 & 2.50 & 50 & 30 & 92.66 \\
\hline 9 & 8.0 & 30 & 2.50 & 200 & 30 & 5.27 \\
\hline 10 & 3.0 & 70 & 0.25 & 50 & 30 & 22.90 \\
\hline 11 & 8.0 & 30 & 0.25 & 50 & 30 & 13.31 \\
\hline 12 & 3.0 & 70 & 2.50 & 50 & 90 & 92.45 \\
\hline 13 & 3.0 & 30 & 0.25 & 50 & 90 & 14.57 \\
\hline 14 & 3.0 & 70 & 0.25 & 200 & 90 & 5.89 \\
\hline 15 & 3.0 & 30 & 0.25 & 200 & 30 & 7.87 \\
\hline 16 & 8.0 & 70 & 0.25 & 50 & 90 & 3.81 \\
\hline 17 & 8.0 & 70 & 2.50 & 50 & 30 & 32.40 \\
\hline 18 & 8.0 & 70 & 0.25 & 200 & 30 & 3.65 \\
\hline 19 & 5.5 & 50 & 1.00 & 100 & 60 & 22.25 \\
\hline
\end{tabular}
tration, respectively. In order to investigate the relation

Table 2 Fractional factorial design matrix and their observed responses for laccase-assisted decolorization of Acid Blue 92 


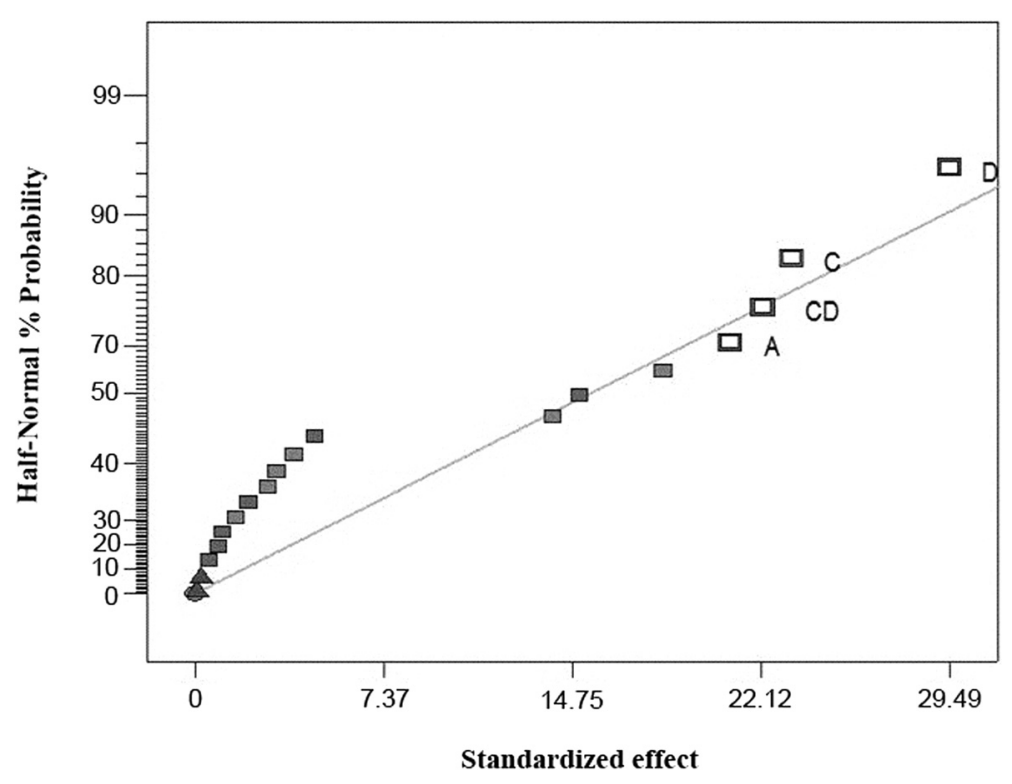

Figure 2 Half-normal probability plot for statistical analysis of fractional factorial design. A: pH; C: Enzyme; D: Dye.

between the independent variables and the responses, contour plots generated by RSM using the DesignExpert software. The response surface plots (Figure 3) present the decolorization of Acid Blue 92 as function of two variables, while the third one kept at a constant level. Surface plots demonstrate an increase in dye decolorization with raising the $\mathrm{pH}$ value. Figure $3 \mathrm{a}$ and Figure 3c clearly show that the decolorization percentage influenced by small alterations of the enzyme activity.

Table 3 D-optimal design matrix containing various conditions and related responses

\begin{tabular}{|c|c|c|c|c|}
\hline Run no. & $\mathrm{pH}$ & Enzyme activity (U/mL) & Dye concentration (mg/L) & Response (decolorization\%) \\
\hline 1 & 8.00 & 0.75 & 75.00 & 4.4 \\
\hline 2 & 1.30 & 1.63 & 137.50 & 2.1 \\
\hline 3 & 5.50 & 3.10 & 137.50 & 99.3 \\
\hline 4 & 3.00 & 0.75 & 200.00 & 5.3 \\
\hline 5 & 5.50 & 1.63 & 137.50 & 19.2 \\
\hline 6 & 5.50 & 1.63 & 137.50 & 14.4 \\
\hline 7 & 3.00 & 0.75 & 75.00 & 11.8 \\
\hline 8 & 5.50 & 1.63 & 137.50 & 15.5 \\
\hline 9 & 3.00 & 2.50 & 200.00 & 10.3 \\
\hline 10 & 3.00 & 2.50 & 75.00 & 42.2 \\
\hline 11 & 5.50 & 1.63 & 32.39 & 58.1 \\
\hline 12 & 5.50 & 1.63 & 137.50 & 16.3 \\
\hline 13 & 5.50 & 1.63 & 137.50 & 17.3 \\
\hline 14 & 8.00 & 2.50 & 200.00 & 14.4 \\
\hline 15 & 9.70 & 3.25 & 137.50 & 6.1 \\
\hline 16 & 8.00 & 2.50 & 75.00 & 92.1 \\
\hline 17 & 5.50 & 1.63 & 242.61 & 4.3 \\
\hline 18 & 5.50 & 1.63 & 137.50 & 18.7 \\
\hline 19 & 8.00 & 0.75 & 200.00 & 0.8 \\
\hline 20 & 5.50 & 0.15 & 137.50 & 4.4 \\
\hline
\end{tabular}


Table 4 Sequential model sum of squares for D-optimal design

\begin{tabular}{llllll}
\hline Source & Sum of squares & $\mathbf{D}_{\mathbf{f}}$ & Mean squares & F-value & P-value \\
\hline Mean vs Total & 10503.78 & 1 & 10503.78 & - & - \\
Linear vs Mean & 9046.07 & 3 & 3015.36 & 2.54 & 0.0013 \\
2FI vs Linear & 2028.02 & 3 & 676.01 & 9.43 & 0.1121 \\
Quadratic vs 2FI & 2671.26 & 3 & 890.42 & 9.38 & 0.003 \\
Cubic vs Quadratic & 820.89 & 4 & 205.22 & - & 0.0089 \\
Residual & 128.66 & 6 & 21.44 & - & - \\
Total & 25198.68 & 20 & 1259.93 & & - \\
\hline
\end{tabular}

\section{Optimization}

By solving the equation (1) and analyzing three dimensional response surface graphs (Figure 3), the optimal levels for $\mathrm{pH}$, enzyme activity, and dye concentration were found to be $8.0,2.5 \mathrm{U} / \mathrm{L}$, and $75 \mathrm{mg} / \mathrm{L}$, respectively. The yield of laccase-catalyzed decolorization of Acid Blue 92 in optimal condition was $94.1 \% \pm 2.61$. The obtained results introduced $\mathrm{pH}$ as the most relevant factor for the enzymatic decolorization of Acid Blue 92. Low yield of decolorization achieved at acidic $\mathrm{pH}$, while $\mathrm{pH} 8.0$ was the optimal $\mathrm{pH}$ where maximum decolorization occurred. In general, most of fungal laccases optimally work at acidic pH levels [26]. For example, the crude laccase of Ganoderma lucidum preferred the acidic range for dye elimination and its decolorization activity decreased significantly at $\mathrm{pH}$ levels above 6.0 [16]. However, Tavares et al. [17] reported that more than $80 \%$ decolorization of Reactive Blue 114 occurred at $\mathrm{pH}$ 7.0-7.5. The maximum removal of Azure B using the purified laccase of Trametes trogii BAFC 463 mediated by 1-hydroxybenzotriazole was achieved at $\mathrm{pH} 7.0$ [18]. In contrast, the laccases originated from bacterial

Table 5 Analysis of variance for D-optimal design

\begin{tabular}{llllll}
\hline Source & Sum of squares & $\mathbf{D}_{\mathbf{f}}$ & Mean squares & F-value & P-value \\
\hline Model & 13745.35 & 9 & 1527.26 & 16.08 & $<0.0001$ \\
A-A & 217.65 & 1 & 217.65 & 2.29 & 0.1610 \\
C-C & 6340.77 & 1 & 6340.77 & 66.78 & $<0.0001$ \\
D-D & 2487.64 & 1 & 2487.64 & 26.20 & 0.0005 \\
AC & 590.82 & 1 & 590.82 & 6.22 & 0.0317 \\
AD & 213.31 & 1 & 213.31 & 2.25 & 0.1648 \\
CD & 1223.89 & 1 & 1223.89 & 12.89 & 0.0049 \\
$A^{2}$ & 548.32 & 1 & 548.32 & 5.77 & 0.0371 \\
$C^{2}$ & 1878.05 & 1 & 1878.05 & 19.78 & 0.0012 \\
$D^{2}$ & 34.93 & 1 & 34.93 & 0.37 & 0.5577 \\
Residual & 949.55 & 10 & 94.95 & - & - \\
Lack of fit & 883.05 & 5 & 176.61 & 13.28 & 0.0065 \\
Pure error & 66.5 & 5 & 13.3 & - & - \\
Cor total & 14694.9 & 19 & - & - & - \\
\hline
\end{tabular}

strains maximally work at alkaline $\mathrm{pH}$ values. For instance, maximum decolorization activity of the purified laccase of Bacillus pumilus strain W3 was achieved at pH 9.0 [27]. The effect of the enzyme activity and dye concentration on decolorization of Acid Blue 92 at $\mathrm{pH} 8.0$ (Figure 2c) revealed that decolorization decreased with increasing dye concentration, but increased with raising the activity of laccase. The results of the present study showed that more than $75 \%$ of the decolorization obtained at dye concentration of $75 \mathrm{mg} / \mathrm{L}$ and laccase activity of $2.5 \mathrm{U} / \mathrm{L}$. Roriz et al. [15] reported that increasing of laccase activity (the crude laccase from Trametes pubescens) positively affected the decolorization of Reactive Black 5. Ashrafi et al. [1] demonstrated significant increase in removal of thirteen synthetic dyes when laccase activity increased in the range of $0.025-0.1 \mathrm{U} / \mathrm{L}$.

\section{Validation of model}

In order to determine the correctness of the model, five verification experiments were performed using the statistically optimal condition. The results showed maximum decolorization efficiency of $90.2 \%$, which is about $99 \%$ of the predicted value, implying a strong similarity between experimental and predicted values calculated from the model that confirms the precision and validity of the model.

\section{Kinetics and energetics of decolorization Kinetic study}

The linear relationship between the initial velocity and dye concentration (Figure 4) indicated that the decolorization is a first order reaction. Based on the Michaelis-Menten and Lineweaver-Burk plots for enzymatic decolorization of Acid Blue 92 (Figure 4a and Figure 4b), the $K_{m}$ and $V_{\text {max }}$ values were $0.48 \mathrm{mM}$ and $227 \mathrm{mM} / \mathrm{min} \mathrm{mg}$, respectively. In the study of Ashrafi et al. [1] who investigated on the ability of laccase for decolorization of a number of synthetic dyes, the lowest $K_{m}(14.8 \mu \mathrm{M})$ found for the anthraquinone-based dye of Disperse Blue 56 followed by the monoazo dye of Acid Red 18 and the triazo dye of Direct Blue 71 with $K_{m}$ value of $25 \mu \mathrm{M}$ and $800 \mu \mathrm{M}$, respectively. In general, the azo dyes that are classified 

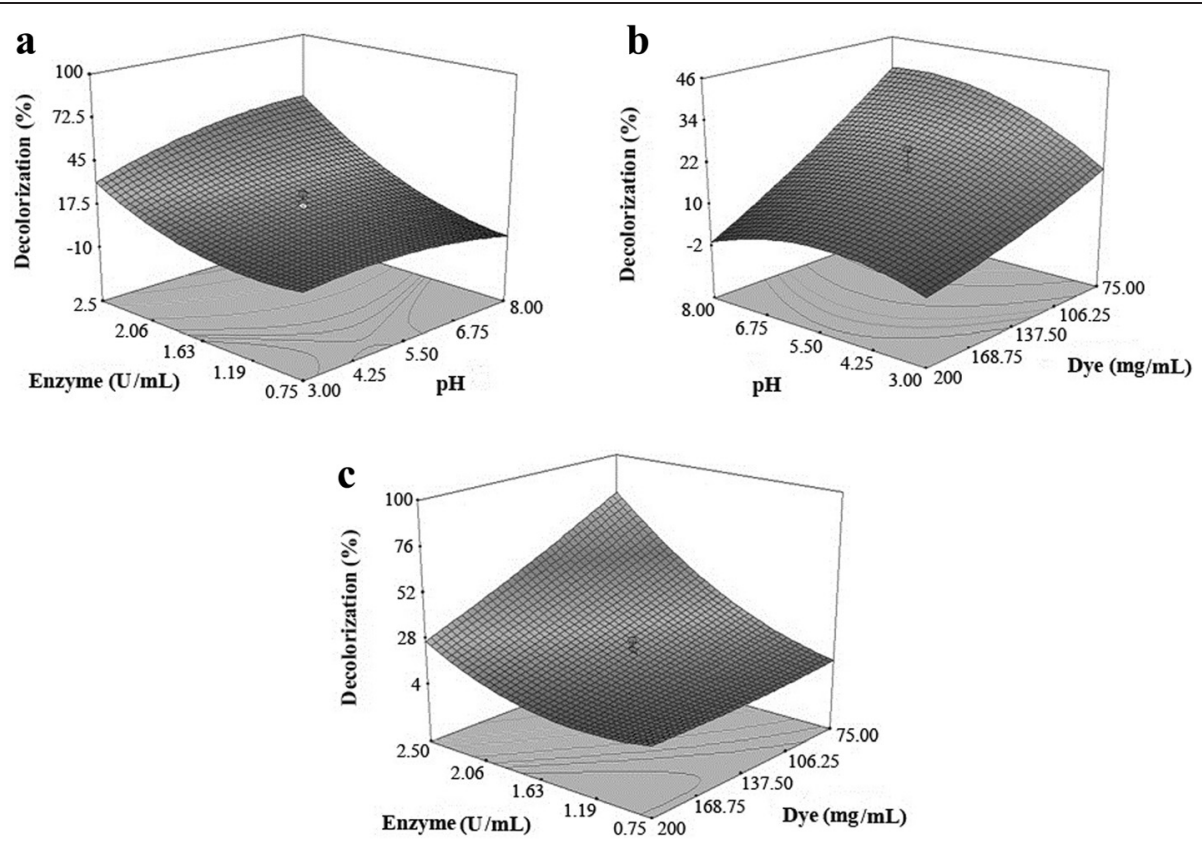

Figure 3 Response surface plot indicating the effects of interactions between a) pH and the enzyme activity, b) pH and the dye concentration, c) the enzyme activity and the dye concentration.

as monoazo, diazo, and triazo, have been identified as recalcitrant colorants for oxidation using laccases compared to that of anthraquinone-based dyes $[1,3]$.

\section{Energetic study}

Energetic results are illustrated in Figure 5. A significant effect of temperature on decolorization of Acid Blue 92 was observed, as decolorization rate increased from 10 to $50^{\circ} \mathrm{C}$. The activation energy (obtained from the slope of Arrhenius plot, Figure 5a) was $39 \mathrm{~kJ} / \mathrm{mol}$, which is typical for the decolorization reaction. The calculated values for $\Delta \mathrm{H}$ and $\Delta \mathrm{S}$ were $40 \mathrm{~kJ} / \mathrm{mol}$ and $131 \mathrm{~J} / \mathrm{mol} \mathrm{K}$, respectively. The positive sign of $\Delta \mathrm{H}$ (Figure $5 \mathrm{~b}$ ) or the negative slope of van't Hoff plot (Figure 5b) implies that the reaction is endothermic.

\section{Dye toxicity}

The obtained results of toxicity evaluation of untreated and laccase-treated dye solution showed that when Acid Blue 92 was used, the calculated GI\% in the presence of $M$. luteus, S. aureus, B. subtilis, E. coli, P. aeruginosa, and $S$. typhi was found to be $60 \pm 1.9,49 \pm 1.4,51 \pm 1.3$, $42 \pm 1.1, \quad 30 \pm 1.1$, and $37 \pm 0.8$, respectively. However, the GI\% for laccase treated dye solution was $31 \pm 3.9,34 \pm$ $2.8,27 \pm 2.5,20 \pm 2.3,17 \pm 0.4$, and $14 \pm 0.9$ in in the presence of $M$. luteus, S. aureus, B. subtilis, E. coli, P. aerugi$n o s a$, and $S$. typhi, respectively, which was significantly
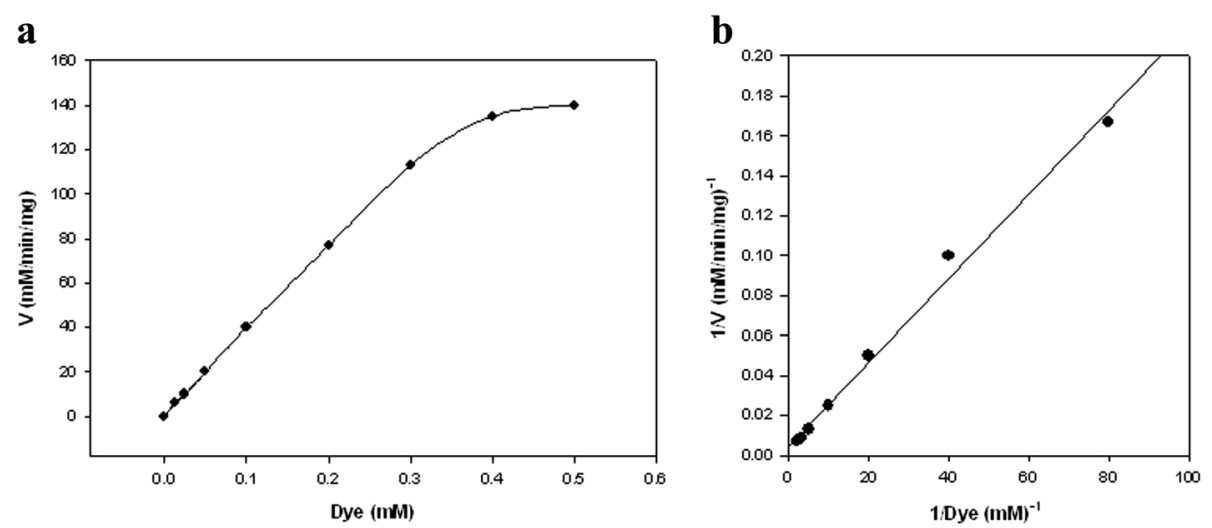

Figure 4 Kinetic study. a) Michaelis-Menten plot, b) Lineweaver-Burk plot. 

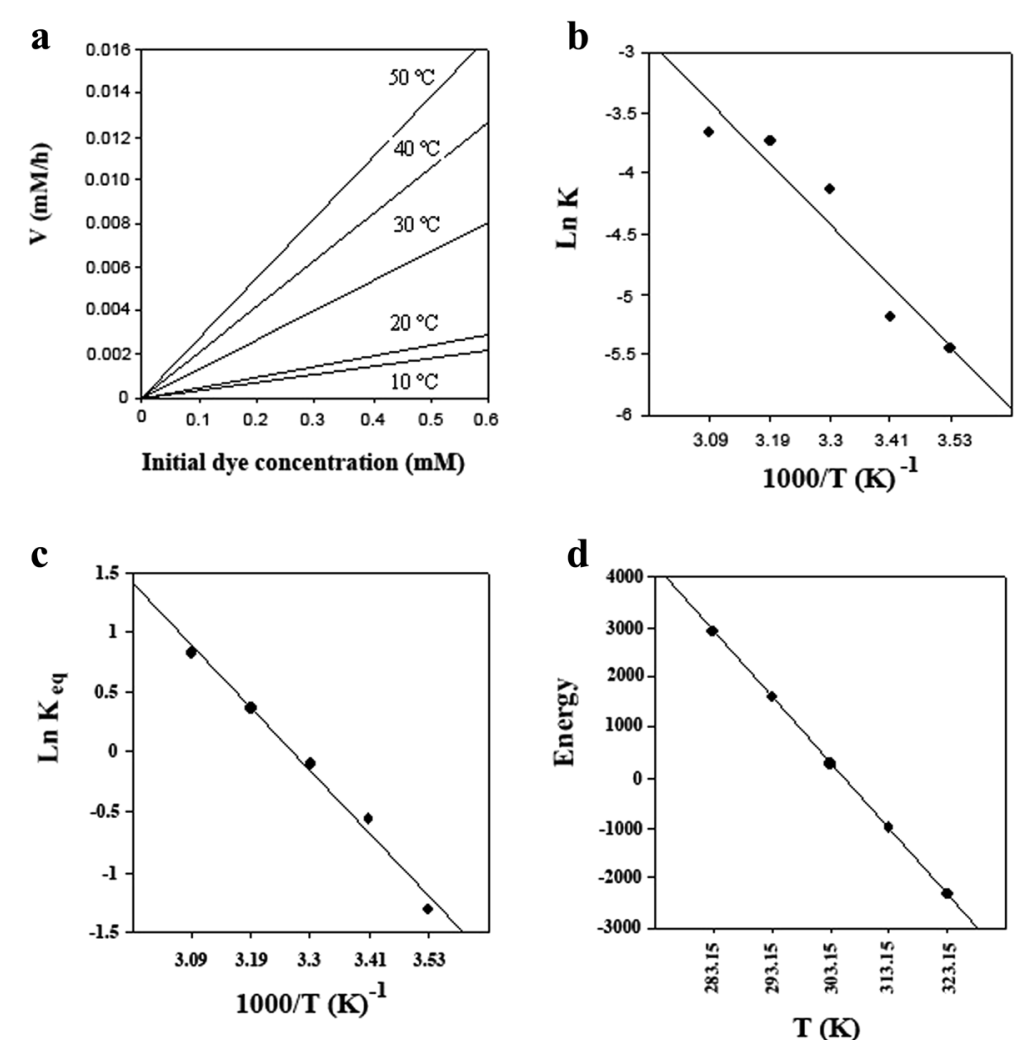

Figure 5 Energetic Study. a) dependence of decolorization rate on temperature $\left(10-50^{\circ} \mathrm{C}\right)$, b) Arrhenius plot, c) van't Hoff plot and, d) Gibbs free energy changes plot.

lower for all bacterial strains. Due to the probable toxicity of produced metabolite following physicochemical or enzymatic treatment of synthetic dyes, many protocols have been developed for determination the toxicity of dyes and related compounds based on the growth inhibition of bacterial (B. megaterium and E. coli), yeast (Saccaromyces cerevisiae), or animal cells (human cervix cells; HeLa), and phytotoxicity studies on plant seeds (Oryza sativa or Triticum aestivum) [1,3]. In the present work, the toxicity of laccase-treated dye sample was significantly reduced compared to that of parent dye. Same results was reported by Palmieri et al. [28] who determined $95 \%$ viability for B. cereus in the presence of sample obtained from enzymatic elimination of Remazol Brilliant Blue R (an anthraquinone dye) using the purified laccase of Pleurotus ostreatus. The growth of B. megaterium and E. coli were reported to be $99 \%$ and $94 \%$, respectively, in the presence of laccasetreated Malachite Green (a triphenylmethane dye). In general, azo dyes have been shown to be more resistant to enzymatic removal compared to other classes of synthetic dyes (like anthraquinone dyes) and provide higher toxicity after enzymatic removal [3,29]. However, Champagne and Ramsay [30] reported lower toxicity for azo dyes (Acid red 27 and Reactive black 5) compared to anthraquinone dyes (Reactive blue 19 and Dispersed blue 3) after treatment using free and immobilized laccases.

\section{Conclusion}

Response surface methodology is an important tool to optimize the conditions for textile dye wastewater treatment. Such statistical approach reduces the number of runs and provides valuable information on possible interactions between the variables and response. The present study was designed to optimize the reaction condition for laccase- catalyzed decolorization of Acid Blue 92. The results indicated $\mathrm{pH}$, enzyme activity, and dye concentration as the most important variables in the enzymatic decolorization of Acid Blue 92. Further studies should be performed on the decolorization of dyes from different families such as triphenylmethan, indigo, and anthraquinone dyes, extensively employing in the textile and chemical industries.

Competing interests

The authors declare that they have no competing interests.

Author's information

Correspondence for statistical experimental design; Mohammad Reza Khoshayand. 


\section{Authors' contributions}

SR and HT carried out the decolorization studies of Acid Blue 92. Production and purification of laccase from $P$. variabile culture and detoxification studies was performed by HF and AA. MM contributed in writing of the manuscript. MRK involved in design of removal experiments, analyzing of data and reviewing of the manuscript. MAF involved in purchasing of required materials and instruments, designing of removal experiments, analyzing of data and reviewing of the manuscript. All authors read and approved the final manuscript.

\section{Acknowledgement}

This work was supported financially by the grant No. 92-03-33-24540 from Tehran University of Medical Sciences, Tehran, Iran to M.A.F.

\section{Author details}

${ }^{1}$ Department of Pharmaceutical Biotechnology, Faculty of Pharmacy and Biotechnology Research Center, Tehran University of Medical Sciences, P.O. Box 14155-6451, Tehran 1417614411, Iran. ²Pharmaceutical Sciences Research Center, Tehran University of Medical Sciences, Tehran 1417614411, Iran. ${ }^{3}$ Department of Medicinal Chemistry, Faculty of Pharmacy, Kerman University of Medical Sciences, Kerman, Iran. ${ }^{4}$ Department of Pharmaceutical Biotechnology, Faculty of Pharmacy, Kerman University of Medical Sciences, Kerman, Iran. ${ }^{5}$ Department of Drug and Food Control, Faculty of Pharmacy and Pharmaceuticals Quality Assurance Research Center, Tehran University of Medical Sciences, Tehran 1417614411, Iran.

\section{Received: 14 November 2014 Accepted: 7 April 2015}

Published online: 16 April 2015

\section{References}

1. Ashrafi SD, Rezaei S, Forootanfar H, Mahvi AH, Faramarzi MA. The enzymatic decolorization and detoxification of synthetic dyes by the laccase from a soil-isolated ascomycete, Paraconiothyrium variabile. Int Biodeter Biodegr. 2013;85:173-81.

2. Mirzadeh SS, Khezri SM, Rezaei S, Forootanfar H, Mahvi AH, Faramarzi MA. Decolorization of two synthetic dyes using the purified laccase of Paraconiothyrium variabile immobilized on porous silica beads. J Environ Health Sci Eng. 2014;12:9

3. Saratale RG, Saratale GD, Chang JS, Govindwar SP. Bacterial decolorization and degradation of azo dyes: a review. J Taiwan Ins Chem Eng. 2011:42:138-57.

4. Khlifi R, Belbahri L, Woodward S, Ellouz M, Dhouib A, Sayadi S. Decolourization and detoxification of textile industry wastewater by the laccase-mediator system. J Hazard Mater. 2010;175:802-8.

5. Aghaie-Khouzani M, Forootanfar H, Moshfegh M, Khoshayand MR, Faramarzi MA. Decolourization of some synthetic dyes using optimized culture broth of laccase producing ascomycete Paraconiothyrium variabile. Biochem Eng J. 2012;60:9-15.

6. Gholami-Borujeni F, Mahvi AH, Nasseri S, Faramarzi MA, Nabizadeh R, Alimohammadi M. Enzymatic treatment and detoxification of acid orange 7 from textile wastewater. Appl Biochem Biotechnol. 2011;165:1274-84.

7. Gholami-Borujeni F, Faramarzi MA, Nejatzadeh-Barandozi F, Mahvi AH. Oxidative degradation and detoxification of textile azo dye by horseradish peroxidase enzyme. Fresenius Environ Bull. 2013;22:739-44.

8. Gholami-Borujeni F, Mahvi AH, Naseri S, Faramarzi MA, Nabizadeh R, Alimohammadi M. Application of immobilized horseradish peroxidase for removal and detoxification of azo dye from aqueous solution. Res J Chem Environ. 2011;15:217-22.

9. Asadgol Z, Forootanfar H, Rezaei S, Mahvi AH, Faramarzi MA. Removal of phenol and bisphenol-A catalyzed by laccase in aqueous solution. J Environ Health Sci Eng. 2014;12:93.

10. Mogharabi M, Faramarzi MA. Laccase and laccase-mediated systems in the synthesis of organic compounds. Adv Synt Catal. 2014;356:897-927.

11. Forootanfar H, Movahednia MM, Yaghmaei S, Tabatabaei-Sameni M, Rastegar H, Sadighi A, et al. Removal of chlorophenolic derivatives by soil isolated ascomycete of Paraconiothyrium variabile and studying the role of its extracellular laccase. J Hazard Mater. 2012;209-210:199-203.

12. Ostadhadi-Dehkordi S, Tabatabaei-Sameni M, Forootanfar $\mathrm{H}$, Kolahdouz S, Ghazi-Khansari M, Faramarzi MA. Degradation of some benzodiazepines by a laccase-mediated system in aqueous solution. Bioresour Technol. 2012;125:344-7.
13. Mogharabi M, Nassiri-Koopaei N, Bozorgi-Koushalshahi M, Nafissi-Varcheh N, Bagherzadeh G, Faramarzi MA. Immobilization of laccase in alginate-gelatin mixed gel and decolorization of synthetic dyes. Bioinorg Chem Appl. 2012;2012:6

14. Jiang $M$, Ten Z, Ding S. Decolorization of synthetic dyes by crude and purified laccases from Coprinus comatus grown under different cultures: The role of major isoenzyme in dyes decolorization. Appl Biochem Biotechnol. 2013;169:660-72

15. Roriz MS, Osma JF, Teixeira JA, Rodríguez-Couto S. Application of response surface methodological approach to optimise Reactive Black 5 decolouration by crude laccase from Trametes pubescens. J Hazard Mater. 2009;169:691-6.

16. Murugesan K, Dhamija A, Nam IH, Kim YM, Chang YS. Decolourization of reactive black 5 by laccase: optimization by response surface methodology. Dyes Pigm. 2007:75:176-84

17. Tavares APM, Cristóvão RO, Loureiro JM, Boaventura RAR, Macedo EA. Application of statistical experimental methodology to optimize reactive dye decolourization by commercial laccase. J Hazard Mater. 2009;162:1255-60.

18. Grassi E, Scodeller P, Filiel N, Carballo R, Levin L. Potential of Trametes trogii culture fluids and its purified laccase for the decolorization of different types of recalcitrant dyes without the addition of redox mediators. Int Biodeter Biodegr. 2011;65:635-43.

19. Myers RH, Montgomery D. Response surface methodology: Process and product optimization using designed experiments. 2nd edition, Wiley, 2002.

20. Forootanfar H, Faramarzi MA, Shahverdi AR, Tabatabaei Yazdi M. Purification and biochemical characterization of extracellular laccase from the ascomycete Paraconiothyrium variabile. Bioresour Technol. 2011;102:1808-14.

21. Faramarzi MA, Forootanfar $\mathrm{H}$. Biosynthesis and characterization of goldnanoparticles produced by laccase from Paraconiothyrium variabile. Colloids Surf, B. 2011:87:23-7.

22. Alberts JF, Gelderblom WCA, Botha A, Vanzyl WH. Degradation of aflatoxin B1 by fungal laccase enzymes. Int J Food Microbiol. 2009;135:47-52.

23. Annuar MSM, Adnan S, Vikineswary S, Chisti Y. Kinetics and energetics of azo dye decolorization by Pycnoporus sanguineus. Water Air Soil Pollut. 2009;202:179-88

24. Khouni I, Marrot B, Amar RB. Decolourization of the reconstituted dye bath effluent by commercial laccase treatment: Optimization through response surface methodology. Chem Eng J. 2010;156:121-33.

25. Daassi D, Zouari-Mechichi H, Frikha F, Martinez JM, Nasri M, Mechichi T. Decolorization of the azo dye Acid Orange 51 by laccase produced in solid culture of a newly isolated Trametes trogii strain. 3. Biotech. 2013;3:115-25.

26. Baldrian P. Fungal laccases - occurrence and properties. FEMS Microbiol Rev. 2006;30:215-42.

27. Guan ZB, Song CM, Zhang N, Zhou W, Xu CW, Zhou LX, et al. Overexpression, characterization, and dye-decolorizing ability of a thermostable, pH-stable, and organic solvent-tolerant laccase from Bacillus pumilus W3. J Mol Catal B: Enzym. 2013;101:1-6.

28. Palmieri G, Cennamo G, Sannia G. Remazol Brilliant Blue R decolourisation by the fungus Pleurotus ostreatus and its oxidative enzymatic system. Enzyme Microb Technol. 2005;36:17-24.

29. Couto SR. Decolouration of industrial azo dyes by crude laccase from Trametes hirsute. J Hazard Mater. 2007;148:768-70.

30. Champagne P-P, Ramsay JA. Dye decolorization and detoxification by laccase immobilized on porous glass beads. Bioresour Technol. 2010;101:2230-5.

\section{Submit your next manuscript to BioMed Central and take full advantage of:}

- Convenient online submission

- Thorough peer review

- No space constraints or color figure charges

- Immediate publication on acceptance

- Inclusion in PubMed, CAS, Scopus and Google Scholar

- Research which is freely available for redistribution 